\title{
Predicting Equivalent Static Density of Fuzzy Ball Drilling Fluid by BP Artificial Neutral Network
}

\author{
Chen Yang, ${ }^{1}$ Zhaohong Wang, ${ }^{2}$ Lihui Zheng, ${ }^{1,3}$ and Dengtian Mao' \\ ${ }^{1}$ College of Petroleum Engineering, China University of Petroleum, Beijing 102249, China \\ ${ }^{2}$ SJVBU, Chevron North America, Bakersfield, CA 93311, USA \\ ${ }^{3}$ CNPC Key Laboratory for Petroleum Drilling Engineering Lost Circulation Control Division, Wuhan 430100, China
}

Correspondence should be addressed to Chen Yang; yangchen@cup.edu.cn

Received 8 January 2015; Revised 23 May 2015; Accepted 14 June 2015

Academic Editor: Michele Iafisco

Copyright (C) 2015 Chen Yang et al. This is an open access article distributed under the Creative Commons Attribution License, which permits unrestricted use, distribution, and reproduction in any medium, provided the original work is properly cited.

\begin{abstract}
A back-propagation artificial neutral network model is built based on 220 groups of PVT experimental data to predict the equivalent static density versus depth for fuzzy ball drilling fluid which is a kind of gas-liquid two-phase material. The model is applied in the Mo80-C well located in Sichuan Province of China; the maximum relative error between calculated results and measured data is less than $2 \%$. By comparing with the multiple regression model, the present model has a higher precision and flexibility. The equivalent static density of fuzzy ball drilling fluid from ground to the depth of $6000 \mathrm{~m}$ is predicted by the present model, and the results show that the equivalent static density of fuzzy ball drilling fluid will decrease slowly with the growth of depth, which indicates that the gas cores of the fuzzy balls still can exist as deep as $6000 \mathrm{~m}$.
\end{abstract}

\section{Introduction}

Fuzzy ball drilling fluid is a gas-liquid two-phase material developed by Zheng et al. [1]. Because of its powerful leak-plugging ability, high low-shear-rate-viscosity, excellent thixotropy, low formation damage, and convenience of preparing [2], it has been applied to drill more than 40 wells all over the world. Although most of them are very successful, there are still many theories about fuzzy ball drilling fluid which need to be improved, among which how to determine the equivalent static density $\rho_{e}(=P / g h$, where $P$ is the static pressure, $h$ is depth) of fuzzy ball drilling at designated depth is one of the most important questions. The drilling fluid with too high equivalent static density will take damage to the formation, while with too low equivalent static density it will make sidewall unstable and even cause well kick and blowout. Especially for underbalanced drilling, the equivalent static density needs to be paid extra attention.

Observed under 1500 times microscope, a lot of different "fuzzy balls" with the structure of "one core, two layers, and three membranes" was found in this material (Figure 1). When it is in the static state, there is an airbag inside the microsphere and there are some fuzzy things which have high gel strength on the outer surface of the microsphere. While it is in the dynamic state, the fuzzy things are cut or scattered and flow ability becomes much better. When dispersed in water, a stable two-phase system of gas and fluid can be formed [3]. The density $\rho$ of the solid-free fuzzy ball drilling fluid in ground condition could be adjusted from 0.8 to $1.0 \mathrm{~g} / \mathrm{cm}^{3}$ according to different compositions. Also, its density can be above $1.0 \mathrm{~g} / \mathrm{cm}^{3}$ by adding inert weighting additives to adapt to near-balanced or underbalanced drilling. With the growth of depth, the pressure and temperature will both increase. Due to the "one core, two layers, and three membranes" structure, the fuzzy ball drilling fluid will compress with the increase of the pressure and expand with the increase of the temperature. The effects of pressure and temperature on the equivalent static density of fuzzy ball drilling fluid are inverse and asynchronous. So, prediction of downhole equivalent static density of the fuzzy ball drilling fluid is a complex and urgent issue.

Methven and Baummann [4] firstly used lab PVT experimental data to calculate downhole equivalent static density of drilling fluid at certain pressure and temperature. Following 


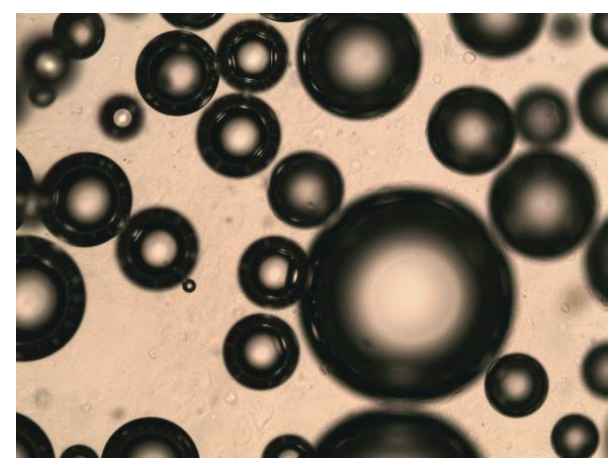

FIGURE 1: Snapshot of fuzzy ball drilling fluid under 1500 times microscope.

their research thought, many researchers built models predicting equivalent static density of different drilling fluids at certain pressure and temperature based on lab PVT data [58]. They all proposed empirical model based on lab PVT data first and then determined the coefficients of the model by certain mathematical method. Their models were all about density versus certain pressure and temperature; however, depth is the most used variable in field, and pressure and temperature both are the function of depth, so it is more convenient and reasonable to establish numerical model predicting equivalent static density versus depth, instead of pressure and temperature.

ANN (artificial neutral network) is an artificial intelligence system which is modeled after the human brain and how it processes the information. BP (back propagation) ANN is currently the most widely used ANN model for one of its multilayer feed forward neural networks by error back propagation. By comparison between BP ANN and multiple regression method in many areas, BP ANN has a better applicability and higher precision than multiple regression method with respect to multifactor analysis problem $[9,10]$. Moreover, multiple regression model is a rigid model, whose coefficients cannot be changed after the model is built even if more data is obtained, but ANN can adjust the weights and thresholds anytime if there is new data, so ANN is a more appropriate choice for the extrapolation prediction problem. Razi et al. [11] developed a BP ANN model to predict the rheological properties of water-based drilling fluids; however, until now, there has not been a BP ANN model to predict equivalent static density versus depth for a multiphase material.

In this paper, BP ANN is introduced to relate the lab PVT data and density of fuzzy ball drilling fluid; the prediction model of equivalent static density versus depth is established based on the built BP ANN. The model is applied in Mo80$\mathrm{C}$ well located in Sichuan Province of China. The predicted results are compared with measured data and the results by multiple regression method.

This method could also be used to predict density for other gas-liquid two-phase material versus different temperature and pressure.

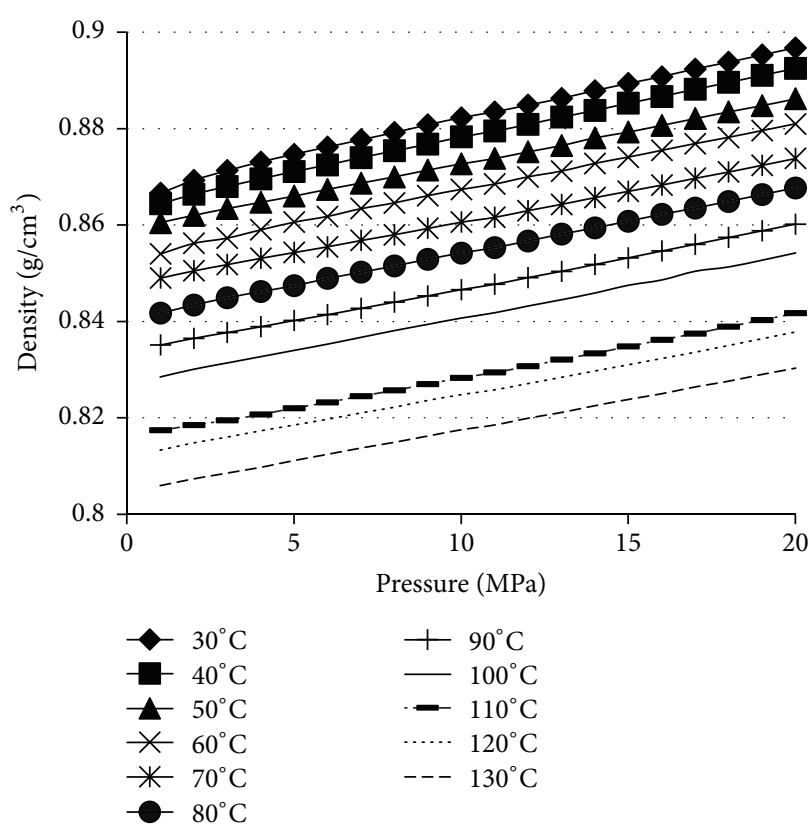

Figure 2: Measured density of fuzzy ball drilling fluid at each pressure and temperature [12].

\section{Prediction Model}

A group of lab PVT experiments was performed to measure the density of the solid-free fuzzy ball drilling fluid with standard state density of $0.85 \mathrm{~g} / \mathrm{cm}^{3}$ under the pressure range of 1-20 MPa and the temperature range of $30-130^{\circ} \mathrm{C}$. Then a BP ANN was established and trained by the 220 density data points and corresponding pressure and temperature. Using this BP network, the prediction model of equivalent static density versus well depth for fuzzy ball drilling fluid was built.

2.1. Lab PVT Tests. The PVT tests were conducted in China University of Petroleum located in Beijing of China [12]. The standard solid-free fuzzy ball drilling fluid was put into the PVT instrument after its mass was measured. By PVT instrument, the volume of the fuzzy ball drilling fluid was measured at each $1 \mathrm{MPa}$ between $1 \mathrm{Mpa}$ and $20 \mathrm{MPa}$ and each $10^{\circ} \mathrm{C}$ between $30^{\circ} \mathrm{C}$ and $130^{\circ} \mathrm{C}$. The experiments results are shown in Figure 2. From the figure, we can see that the density of fuzzy ball drilling fluid increases with the growth of pressure and decreases with the growth of temperature. The trend of density versus temperature or pressure is nearly linear, but, with the increase of well depth, the temperature and the static pressure caused by the overburden fluid are nonlinear, so the equivalent static density of the fuzzy ball drilling fluid versus well depth is also nonlinear, and a sophisticated model is needed to predict its distribution.

2.2. BP ANN. BP ANN is a multilayer feed forward neural network by error back propagation which was proposed in 1986 [13]. The learning algorithm can update the weights and thresholds automatically according to the error back propagation. BP ANN can provide several advantages over 


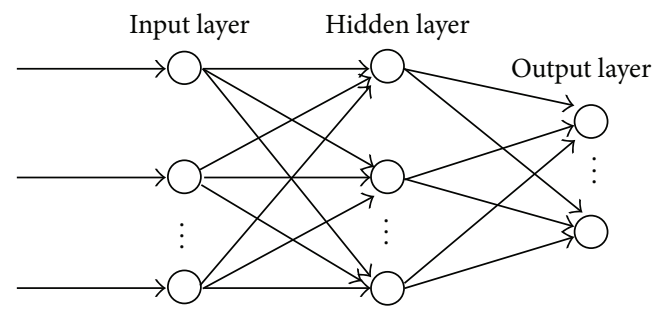

FIGURE 3: Topological structure of BP ANN.

conventional regression models. They are claimed to possess the property to learn from a set of data without the need for a full specification of the decision model; they are believed automatically to provide any needed data transformations. They are also claimed to be more robust in the presence of noise and distortion [14]. So, BP ANN is a better choice for multiobjective prediction problem.

BP ANN is divided into input layer, hidden layer, and output layer. The topological structure of the BP ANN is shown in Figure 3. In the present study, input data includes pressure $P$ and temperature $T$, and the output data is the density of fuzzy ball drilling fluid $\rho$.

Different from conventional multiple regression method, not only can polynomial be used to describe the relationship between sets, but also exponential function, logarithmic function, and other functions can be adopted by BP ANN. These functions between different sets are called activation functions in BP ANN. The activation function used in the present paper for hidden layer is

$$
\tan \operatorname{sig}(x)=\frac{2}{\left(1+e^{(-2 x)}\right)}-1
$$

and for output layer is

$$
\operatorname{purlin}(x)=x,
$$

where $x$ is the input data from the previous layer to the next layer. So, the density $\rho$ could be expressed by the composition of $P, T$ and activation functions,

$$
\begin{aligned}
\rho_{\text {out }} & =\sum_{i=1}^{p} w_{1 i}^{2} \operatorname{tansig}\left(w_{i 1}^{1} P+w_{i 2}^{1} T+b_{i}^{1}\right)+b_{1}^{2} \\
& =\operatorname{NET}(P, T),
\end{aligned}
$$

where NET is the BP network model, $p$ is the number of neurons, $P$ and $T$ represent the input pressure and temperature, $w_{i j}^{k}$ is the weight of the $i$ th neurons and the $j$ th input data at the $k$ th layers, and $b_{i}^{k}$ is the threshold of the $i$ th neuron at the $k$ th layer. $\rho_{\text {out }}$ is the output density of the fuzzy ball drilling fluid, for the target output $\rho_{r}$, and an error $e(n)$ can be defined as

$$
e(n)=\rho_{r}(n)-\rho(n) .
$$

We define the instantaneous value of the error energy for neuron $i$ as $1 / 2 e_{i}^{2}(n)$. So, the total error energy for the entire network is obtained by summing instantaneous values over all neurons in the output layer, as

$$
E(n)=\frac{1}{2} \sum_{i \in C} e_{i}^{2}(n),
$$

where the set $C$ includes all neurons in the output layer of the network. Let $N$ denote the total number of samples contained in the training set. The average squared error energy is obtained by summing $E(n)$ over all $n$ and then normalizing it with respect to size $N$, as shown by

$$
E_{\mathrm{av}}=\frac{1}{N} \sum_{n=1}^{N} E(n) .
$$

The average error energy $E_{\mathrm{av}}$ is a function of all the free parameters of the network. For a given training set, $E_{\mathrm{av}}$ represents the cost function as a measure of learning performances. The objective of the learning process is to adjust the free parameters of the network to minimize $E_{\mathrm{av}}$. To do this minimization, the weights are updated on a sample-bysample basis for one iteration.

The correction of the weight $w_{i j}(n)$ could be expressed in the form

$$
\Delta w_{i j}(n)=-\eta \cdot \frac{\partial E(n)}{\partial w_{i j}(n)},
$$

where $\eta$ is a positive constant that determines the rate of learning and $w_{i j}(n)$ is the value of synaptic weight. Having computed the adjustment $w_{i j}(n)$, the updated value of synaptic weight is determined by

$$
w_{i j}(n+1)=w_{i j}(n)+\Delta w_{i j}(n),
$$

where $w_{i j}(n)$ and $w_{i j}(n+1)$ can be viewed as the old and new values of the synaptic weight $w_{i j}$, respectively. After all the new weight is obtained, the training process is finished. The trained network can be used to predict the density at designated pressure and temperature.

Generally speaking, when building a BP ANN, besides the data used to establish the network, there still has to be some other data used to test the model. The BP ANN is not valid until it is tested. The MSE (mean square error) and the relative coefficient $R$ are used to evaluate the performance of the BP network model.

The MSE of the BP network model is

$$
\operatorname{MSE}=\frac{1}{N} \sum_{i=1}^{N}\left(\rho_{\text {out }}(P, T)-\rho_{r}(P, T)\right)^{2} .
$$

In order to enhance the generalization ability of the BP network model, the following equation is adopted as the training objective:

$$
\mathrm{Obj}=1-\lambda \mathrm{MSE}+\lambda D(W),
$$

where $D(W)$ is the mean error of the weights matrix.

Both the train error and test error will decrease with the training process until the preset precision is satisfied. 
The error of the present BP network model is shown in Figure 4. The minimum train error and test error were achieved about $10^{-5}$ after 305 steps of training. The final relative coefficients of the BP network are over 0.998, which indicates that the BP network has high precision and strong generalization ability.

2.3. Prediction Model of Equivalent Static Density. The static pressure of drilling fluid at certain depth is equal to its overburden hydrostatic fluid column pressure, giving

$$
P=\rho g h+P_{0},
$$

where $P_{0}$ is the atmospheric pressure and $\rho$ is the equivalent static pressure at depth of $h$. The derivative of (11) with respect to $h$ is

$$
\frac{1}{g} \frac{d P}{d h}=\rho .
$$

Taking (3) into (12) gives

$$
\begin{aligned}
\frac{1}{g} \frac{d P}{d h} & =\sum_{i=1}^{p} w_{1 i}^{2} \operatorname{tansig}\left(w_{i 1}^{1} P+w_{i 2}^{1} T+b_{i}^{1}\right)+b_{1}^{2} \\
& =\operatorname{NET}(P, T) .
\end{aligned}
$$

The boundary condition of (13) is

$$
P(h=0)=P_{0} \text {. }
$$

Mesh the computational area along the depth direction, and discretize (13) with one-dimensional explicit differential algorithm, giving

$$
\frac{1}{g} \frac{P_{d+1}-P_{d}}{\Delta h}=\operatorname{NET}\left(P_{d}, T_{d}\right),
$$

where $P_{d}$ and $T_{d}$ are the pressure and temperature at the $d$ th grid. Rearranging (15), the $P_{d+1}$ can be calculated by

$$
P_{d+1}=\operatorname{NET}\left(P_{d}, T_{d}\right) g \Delta h+P_{d} .
$$

The equivalent static density at the $(d+1)$ th grid could be calculated by $\rho_{e}=P_{d+1} / g h$.

The temperature of drilling fluid can be approximated as the formation temperature after full heat exchange as

$$
T_{d}=T_{0}+a \Delta h d,
$$

where $T_{0}$ is the ground temperature and $a$ is the geothermal gradient.

If the density of practical fuzzy ball drilling fluid on the ground is $\rho_{0}^{\prime}$ instead of $\rho_{0}$, we have to modify the calculated equivalent static density by

$$
\rho^{\prime}(h)=\alpha \rho(h),
$$

where

$$
\alpha=\frac{\rho_{0}^{\prime}}{\rho_{0}}
$$

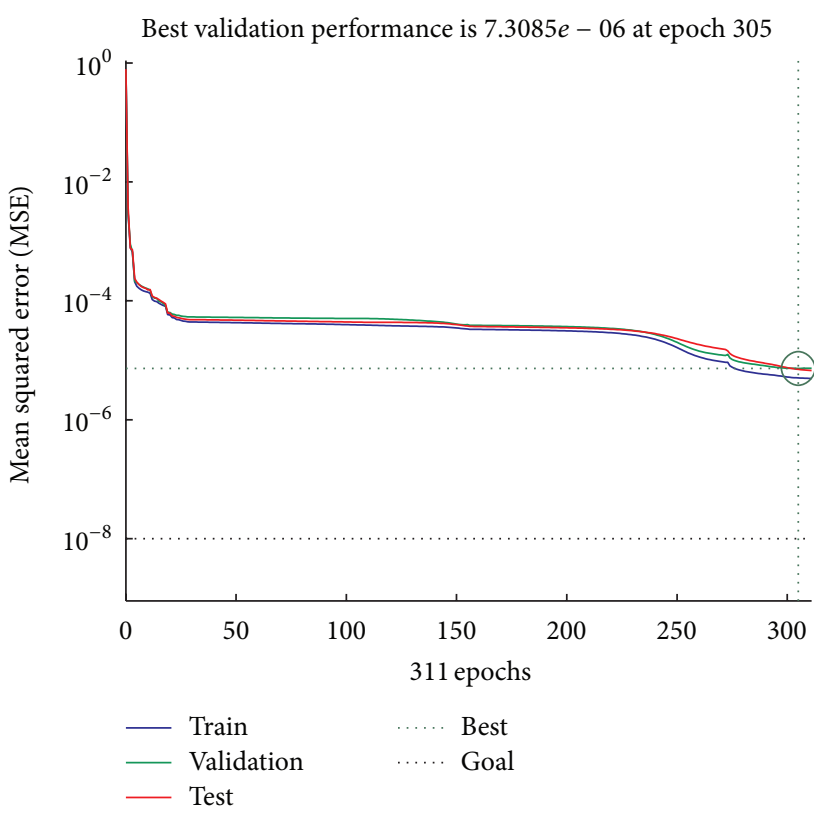

FIGURE 4: Train error, test error, and validation error of the BP ANN during training.

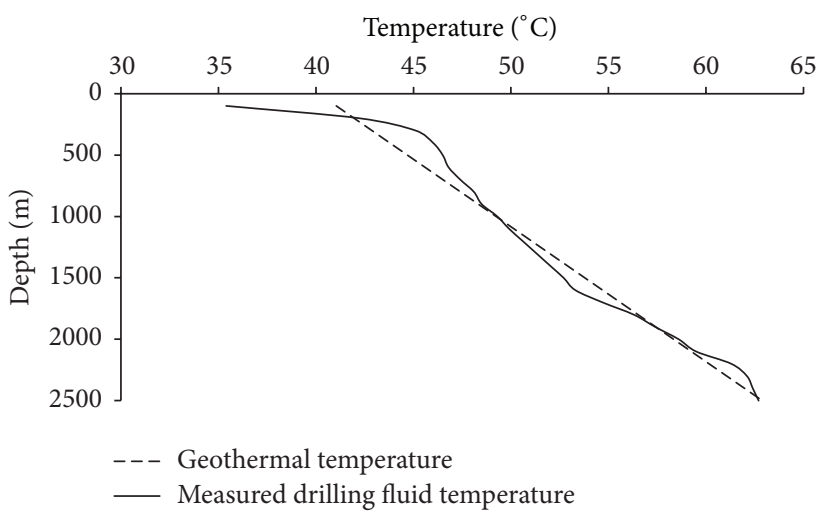

Figure 5: Calculated and measured temperature versus depth in Mo80-C well.

\section{Model Application}

Mo80-C well is sidetracking horizontal well located in Sichuan Province of China. The target horizon is at the depth of $2728.00 \mathrm{~m}$, the average formation pressure is $32.61 \mathrm{MPa}$, and the geothermal distribution is

$$
T=40.134+0.0091 h
$$

The measured and calculated formation temperatures are shown in Figure 5. From the figure, we can see that the measured and calculated temperatures match well except for the near ground zone. That is mainly because that the temperature sensor is located in the drilling fluid, and the drilling fluid near ground is affected greatly by the ground working condition, so the heat of which does not exchange sufficiently with the formation nearby. 


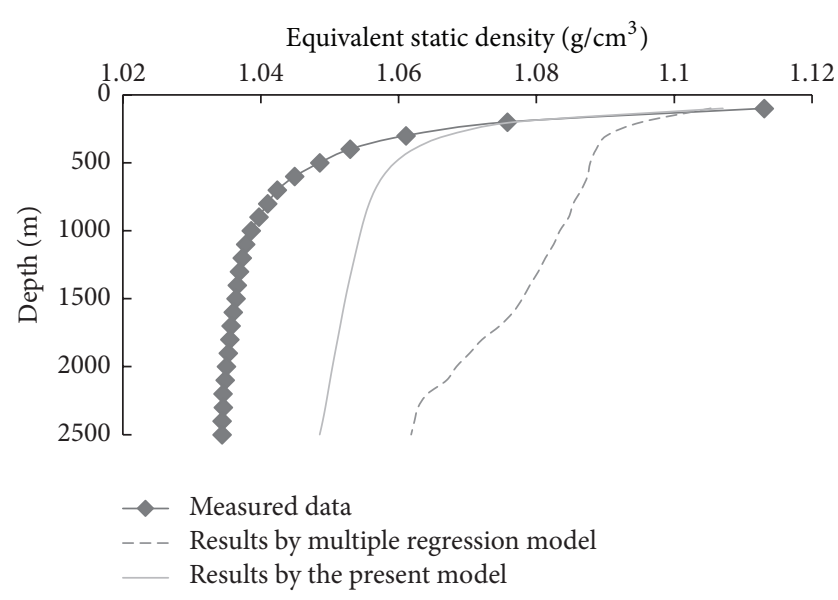

FIGURE 6: Equivalent static density by the present model, multiple regression model, and filed measurement.

The fuzzy ball drilling fluid with solid was used to drill the Mo80-C well. The density on the ground was measured to be $1.02 \mathrm{~g} / \mathrm{cm}^{3}$ and the volumetric percentage of solid is $8 \%$. So the density of corresponding solid-free drilling fluid on the ground $\rho_{0}^{\prime}$ satisfies

$$
1.02=0.08 \times \rho_{\text {solid }}+(1-0.08) \times \rho_{0}^{\prime},
$$

where $\rho_{\text {solid }}$ is the density of solid which is $2.5 \mathrm{~g} / \mathrm{cm}^{3}$ in the present study, so $\rho_{0}^{\prime}$ is calculated to be $0.89 \mathrm{~g} / \mathrm{cm}^{3}$, and $\alpha$ in (19) is

$$
\alpha=\frac{0.89}{0.85}=1.05
$$

The predicted density of solid-free fuzzy ball drilling fluid $\rho^{\prime}(h)$ has to be converted to density of solid fuzzy ball drilling fluid $\rho_{s}^{\prime}(h)$ with

$$
\rho_{s}^{\prime}(h)=\frac{1.02}{0.08}+(1-0.08) \times \frac{\rho_{0}^{\prime}}{\rho^{\prime}(h)} .
$$

The present model is used to calculate the equivalent static density of fuzzy ball drilling fluid versus depth in the Mo80- $\mathrm{C}$ well. The predicted results and measured data are compared in Figure 6. In order to evaluate the advantage of the present model, the results of multiple regression model proposed by Wang et al. [12] are also shown in the same figure.

From Figure 6, we can see that the results by the present BP network are closer to the measured data compared with the multiple regression models. The maximum relative error is less than $2 \%$. The trend of predicted equivalent static density of fuzzy ball drilling fluid is the same as measured data. The difference between them may be caused by the temperature error near ground as shown in Figure 7.

After validation, the model is used to predict the equivalent static density of fuzzy ball drilling fluid as deep as $6000 \mathrm{~m}$. The predicted results are shown in Figure 7. From the results, we can see that, with the increasing of depth, the equivalent static density of fuzzy ball drilling fluid will decrease slowly;

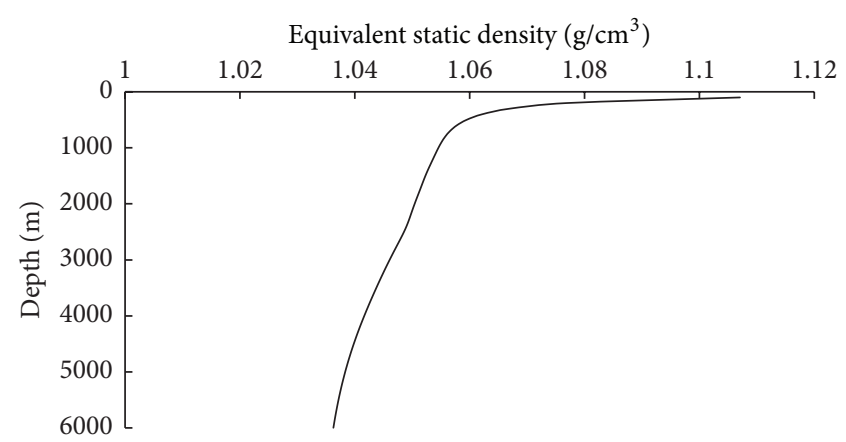

FIgURE 7: Predicted equivalent static density from ground to the depth of $6000 \mathrm{~m}$ by the present model.

this conclusion is very important, which indicates that the gas cores can still exist in fuzzy ball drilling fluid as deep as $6000 \mathrm{~m}$, which means the fuzzy ball drilling fluid can be used in deep well and maintain its excellent performance.

\section{Conclusion}

Fuzzy ball drilling fluid is a gas-liquid two-phase material with the structure of "one core, two layers, and three membranes." A BP ANN was built in this paper to relate the density of fuzzy ball drilling fluid with pressure and temperature. Based on this BP network, a numerical model is established to predict the downhole equivalent static density of fuzzy ball drilling fluid versus depth. The model was applied in the Mo80-C well, by comparing with measured data and results by a multiple regression model; the BP ANN was proved to have a higher precision. Moreover, the BP ANN model is a flexible self-adjusting system, which can update weights and thresholds anytime if there is new input data. So, BP ANN is a better choice for the prediction of equivalent static density of fuzzy ball drilling fluid.

Using the present model, the equivalent static density of fuzzy ball from 0 to the depth of $6000 \mathrm{~m}$ was predicted. The results illustrate that the equivalent static density of fuzzy ball drilling fluid will decrease slowly with the growth of depth, which indicates that the gas-core still can exist as deep as $6000 \mathrm{~m}$.

Moreover, the method used in the present study also could be used to predict the equivalent static density of another multiphase material which is affected greatly by temperature and pressure.

\section{Conflict of Interests}

The authors declare that there is no conflict of interests regarding the publication of this paper. 


\section{Acknowledgments}

This study was supported by National Natural Science Foundation of China (51304227) and Science Foundation of China University of Petroleum, Beijing (2462015YQ0213). Thanks are due for all the efforts LihuiLab Company have made to support this study.

\section{References}

[1] L. H. Zheng, L. C. Kong, Y. Cao, H. Y. Wang, Z. X. Han, and X. Q. He, "The mechanism for fuzzy-ball working fluids for controlling \& killing lost circulation," Chinese Science Bulletin, vol. 55, no. 35, pp. 4074-4082, 2010.

[2] L. H. Zheng, X. H. Wan, H. J. Zhang, L. J. Chi, and K. W. Peng, "A novel multifunctional bionic fuzzy-ball drilling fluid," Advanced Materials Research, vol. 236-238, pp. 608-615, 2011.

[3] L. H. Zheng, L. Kong, Y. Cao, H. Wang, and Z. Han, "A new fuzzy ball working fluid for plugging lost circulation paths in depleted reservoirs," Petroleum Science and Technology, vol. 30, no. 24, pp. 2517-2530, 2012.

[4] N. E. Methven and R. Baummann, "Performance of oil muds at high temperatures," in Proceedings of the SPE European Spring Meeting, SPE-3743-MS, Amsterdam, The Netherlands, May 1972.

[5] G. W. Krook and T. D. Boyce, "Downhole density of heavy brines," SPE 12490, 1984.

[6] I. M. Kutasov, "Empirical correlation determines downhole mud density," Oil \& Gas Journal, vol. 86, no. 50, pp. 61-63, 1988.

[7] E. J. Peters, M. E. Chevenver, and A. M. Alhamadah, "OILMUD: a microcomputer program for predicting oil-based mud densities and static pressures," SPE Drilling Engineering, vol. 6, no. 1, pp. 57-59, 1991.

[8] E. Karstad and B. S. Aadnoy, "Density behavior of drilling fluids during high pressure high temperature drilling operations," in Proceedings of the IADC/SPE Asia Pacific Drilling Technology, SPE-47806-MS, Jakarta, Indonesia, September 1998.

[9] N. Nguyen and A. Cripps, "Predicting housing value: a comparison of multiple regression analysis and artificial neural networks," Journal of Real Estate Research, vol. 22, no. 3, pp. 313336, 2001.

[10] J. Y. Kim, B. H. Cho, S. M. Im et al., "Comparative study on artificial neural network with multiple regressions for continuous estimation of blood pressure," in Proceedings of the 27th Annual International Conference of the IEEE Engineering in Medicine and Biology Society, pp. 6942-6945, Shanghai, China, 2005.

[11] M. M. Razi, M. Mazidi, F. M. Razi, H. Aligolzadeh, and S. Niazi, "Artificial neural network modeling of plastic viscosity, yield point, and apparent viscosity for water-based drilling fluids," Journal of Dispersion Science and Technology, vol. 34, no. 6, pp. 822-827, 2013.

[12] J. F. Wang, L. H. Zheng, Z. X. Han et al., "Prediction of equivalent static density of water-based fuzzy ball drilling fluids with multiple regression method," Oil Drilling \& Production Technology, vol. 34, no. 2, pp. 33-36, 2012 (Chinese).

[13] D. E. Rumelhart and J. L. McClelland, Parallel Distributed Processing: Explorations in the Microstructure of Cognition, MIT Press, Cambridge, Mass, USA, 1986.

[14] T. D. Parsons, A. A. Rizzo, and J. G. Buckwalter, "Back propagation and regression: comparative utility for neuropsychologists," Journal of Clinical and Experimental Neuropsychology, vol. 26, no. 1, pp. 95-104, 2004. 

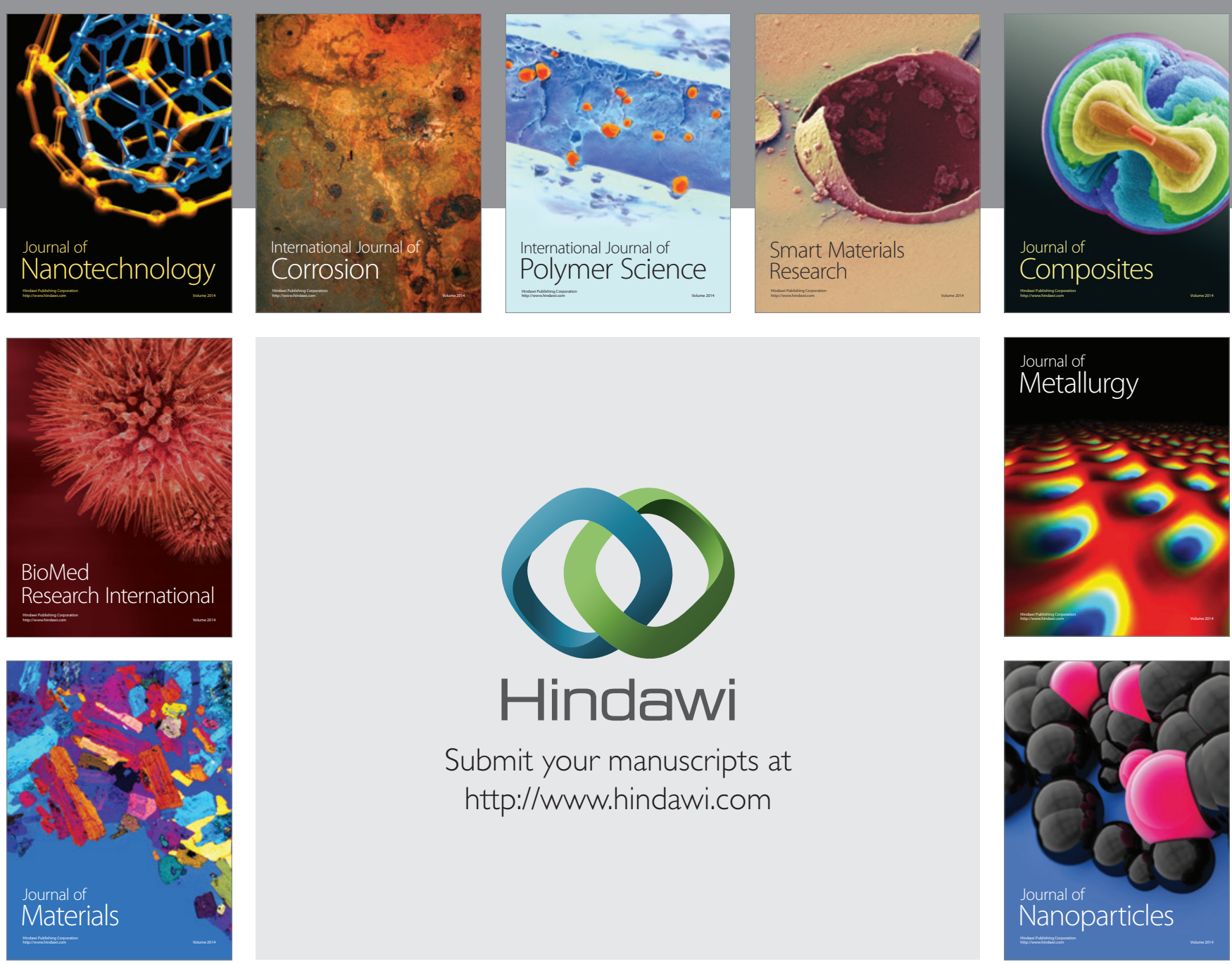

Submit your manuscripts at http://www.hindawi.com
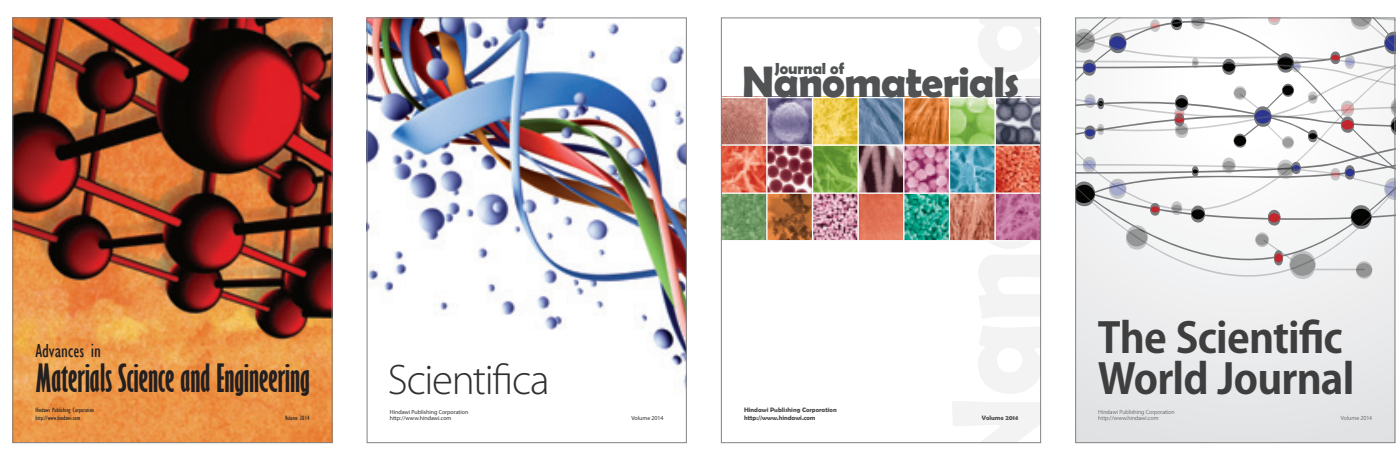

\section{The Scientific World Journal}
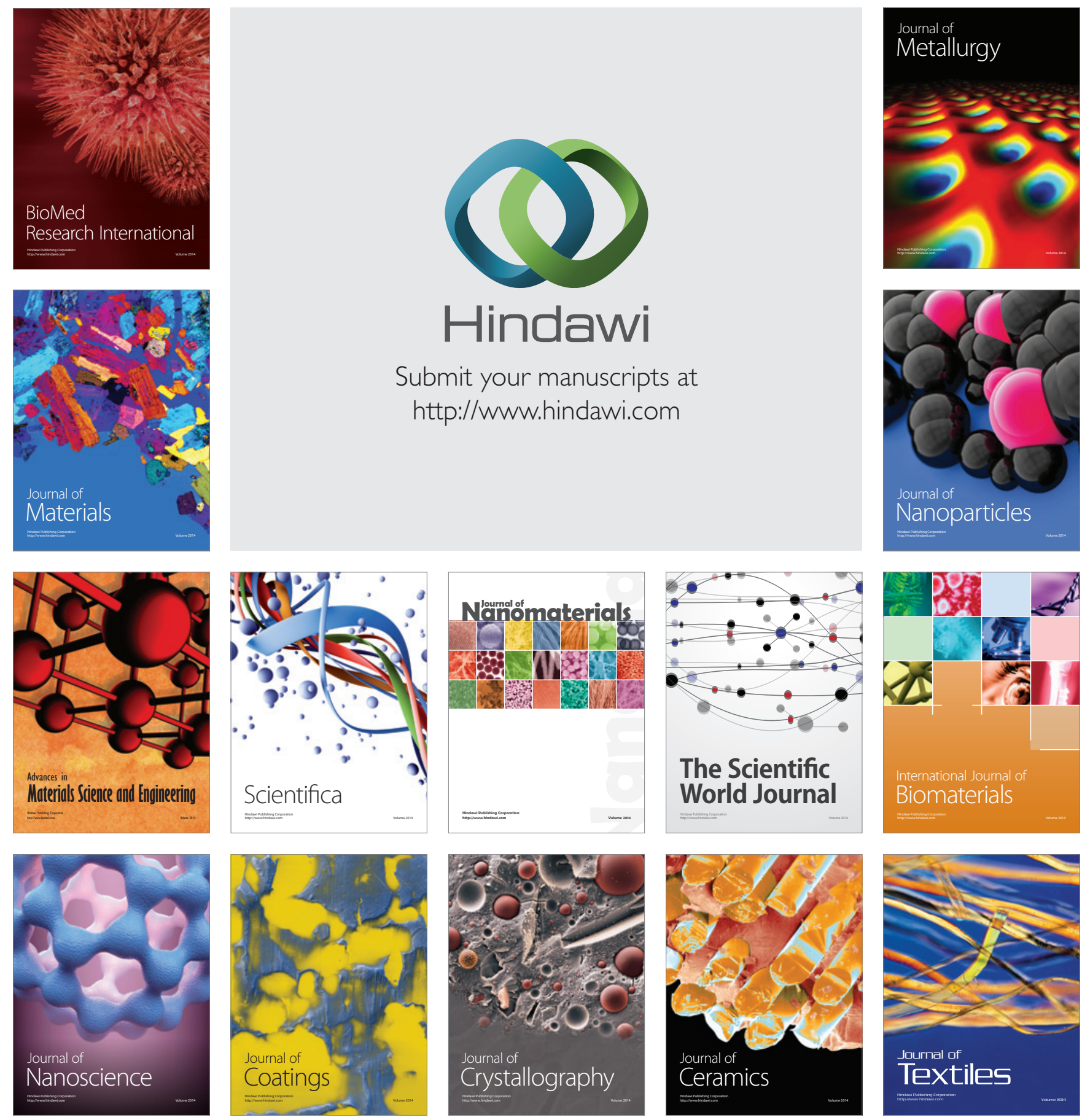